\title{
Localization of Potential Serotonergic Facilitator Neurons in Aplysia by Glyoxylic Acid Histofluorescence Combined with Retrograde Fluorescent Labeling
}

\author{
Robert D. Hawkins \\ Center for Neurobiology and Behavior, College of Physicians and Surgeons, Columbia University, and New York State \\ Psychiatric Institute, New York, New York 10032
}

\begin{abstract}
A variety of evidence suggests that 5-HT participates in presynaptic facilitation of the siphon sensory cells contributing to dishabituation and sensitization of the gill- and siphonwithdrawal reflex in Aplysia. Most recently, Glanzman ot al. (1989) have shown that the 5-HT neurotoxin 5,7-DHT markedly reduces both the synaptic facilitation and behavioral dishabituation produced by tail shock. To provide more direct evidence for a role of 5-HT, I have used histological techniques to try to locate individual serotonergic facilitator neurons. I first used a modification of the glyoxylic acid histofluorescence technique to map serotonergic and dopaminergic neurons in the CNS of Aplysia. Intracellular fluorescent labeling combined with histofluorescence indicates that the previously identified L29 facilitator neurons are not serotonergic. Nerve transection experiments suggest that most of the perisomatic 5-HT histofluorescence in the abdominal ganglion (the location of the siphon sensory cells) comes from neurons whose cell bodies are located in the pedal or cerebral ganglia. As there are at least 500 serotonergic neurons in those ganglia, I combined retrograde fluorescent labeling with histofluorescence to identify a small subset of those neurons which send processes to the abdominal ganglion and are therefore potential serotonergic facilitators. In the following paper, Mackey et al. (1989) show that stimulation of $\mathbf{2}$ of those neurons in the cerebral ganglia (the CB1 cells) produces presynaptic facilitation of the siphon sensory cells contributing to dishabituation and sensitization of the withdrawal reflex.
\end{abstract}

A variety of evidence suggests that 5-HT participates in presynaptic facilitation of the siphon sensory cells contributing to dishabituation and sensitization of the gill- and siphon-withdrawal reflex in Aplysia. First, 5-HT mimics sensitizing cutaneous stimuli or nerve shock in producing presynaptic facilitation and its biophysical and biochemical correlates in the sensory cells (Brunelli et al., 1976; Klein and Kandel, 1978, 1980; Bernier et al., 1982). Second, 5-HT is endogenous to the

\footnotetext{
Received Feb. 27, 1989; revised June 6, 1989; accepted June 12, 1989.

This work was supported by a grant from the National Institute of Health (MH26212). I thank D. Glanzman, L. Eliot, E. Kandel, I. Kupfermann, and J. Schwartz for their comments, K. Hilten and L. Katz for preparing the figures, and H. Ayers and A. Krawetz for typing the manuscript.

Correspondence should be addressed to Dr. Robert D. Hawkins, Center for Neurobiology and Behavior, College of Physicians and Surgeons, Columbia University, 722 West 168th Street, New York, NY 10032.

Copyright $\odot 1989$ Society for Neuroscience $0270-6474 / 89 / 124214-13 \$ 02.00 / 0$
}

abdominal ganglion, where 5-HT immunoreactive fibers are found in close proximity to the sensory cells (Kistler et al., 1985). Third, the 5-HT antagonist cinanserin reduces facilitation of the sensory cells (Brunelli et al., 1976), and the 5-HT neurotoxin 5,7-DHT markedly reduces both facilitation and behavioral dishabituation (Glanzman et al., 1989). However, this evidence is all indirect, and at least 2 other endogenous transmitters (the small cardioactive peptide SCP and the unknown transmitter of the $\mathrm{L} 29$ cells) can also produce facilitation of the sensory cells (Abrams et al., 1984; Hawkins et al., 1981b). The contribution of 5-HT to facilitation, dishabituation, and sensitization has therefore been uncertain.

To provide more direct evidence for a role of 5-HT in facilitation, dishabituation, and sensitization, it is desirable to identify individual serotonergic facilitator neurons. In this paper, I report on the use of histological techniques to locate a set of serotonergic neurons in the nervous system of Aplysia that are potential facilitators. In the first part of the paper, I describe experiments in which I used a modification of the glyoxylic acid histofluorescence technique to map serotonergic neurons in Aplysia and present evidence that suggests the technique is fairly specific for 5-HT. I then review experiments in which I combined the glyoxylic acid method with nerve transection and retrograde fluorescent labeling to identify a subset of serotonergic neurons that send processes to the vicinity of the siphon sensory cells. In the following paper, Mackey et al. (1989) show that stimulation of 2 of those neurons, the left and right CB1 cells, produces presynaptic facilitation of the sensory cells.

\section{Materials and Methods}

Glyoxylic acid histofluorescence. The glyoxylic acid histofluorescence technique is a relatively fast and easy method for visualizing monoaminergic neurons in sections of nervous tissue (Lindvall and Bjorklund, 1974). I used a slight modification of the methods of Goldstein (1984; Goldstein and Schwartz, 1989), Barber (1982), and Bolstad et al. (1979), which are in turn modifications of the method of de la Torre and Surgeon (1976), to map the distribution of monoaminergic neurons in the nervous system of Aplysia. Ganglia from adult $(30-100 \mathrm{gm})$ or juvenile (0.5-5.0 gm) Aplysia californica (supplied by Sea Life Supply, Sand City, $\mathrm{CA}$, and the Howard Hughes Medical Institute mariculture facility, Woods Hole, MA) were soaked in a solution of $25 \%$ sucrose, $0.1 \mathrm{M}$ phosphate buffer (pH 7.4) at $4^{\circ} \mathrm{C}$ for at least $1 \mathrm{hr}$, or until they sank. They were then quickly frozen in a drop of O.C.T. embedding medium (Miles, Inc., Elkhart, IN) and cut into $30-\mu \mathrm{m}$ sections in a cryostat. The sections were picked up on clean glass slides and immersed in an icecold solution of $1 \%$ glyoxylic acid, $25 \%$ sucrose, 25 mM HEPES buffer (pH 7.0) for $5 \mathrm{~min}$. The slides were then blotted around the edges with a tissue, dried under a stream of cool air for $15-30 \mathrm{~min}$, and heated in a $100^{\circ} \mathrm{C}$ oven for $5 \mathrm{~min}$. The sections were coverslipped with mineral 
oil and viewed with a D filter cube (excitation filter $355-425 \mathrm{~nm}$, mirror $455 \mathrm{~nm}$, barrier filter $460 \mathrm{~nm}$ ) on a Leitz epifluorescence microscope. Using this technique, 5-HT appears yellow-green and catecholamines appear blue. In Aplysia, blue fluorescence probably corresponds to dopamine, since that is the only catecholamine detectable with biochemical techniques (Carpenter et al., 1971; McCaman et al., 1973; Gospe et al., 1981). Goldstein (1984; Goldstein and Schwartz, 1989) has shown by microspectrofluorimetry that the glyoxylic acid emission spectra in $A p l y$ sia agree well with 5-HT and dopamine standards. Control slides treated similarly but dipped in a solution without glyoxylic acid cxhibitcd no yellow-green or blue fluorescence, but only reddish autofluorescence. The fluorescent images were photographed with Kodak Ektachrome 400 film for slides, which were then either converted to prints or projected onto paper, traced on a digitizing tablet, and entered into an IBM PC for reconstruction of the ganglia using commercially available software (PC3D, Jandel Scientific, Corte Madera, CA).

Intracellular fluorescent labeling. In some experiments, ganglia from adult $(50-100 \mathrm{gm})$ animals were partially desheathed and individual cells were identified with standard electrophysiological techniques (Frazier et al., 1967; Hawkins et al., 1981a). The identified cell was then injected iontophoretically with the fluorescent dye lissamine rhodamine B (LRB) (Gurr, High Wycombe, England). Injection electrodes were filled with a $5 \%$ soultion of dye in water and had resistances approximately 5 times as high as comparable electrodes filled with $2.5 \mathrm{M} \mathrm{KCl}$. Dye was injected by passing $500 \mathrm{msec}$ hyperpolarizing pulses (1-2 nA) at $1 \mathrm{~Hz}$ until the cell was faintly pink (5-90 min, depending on the size of the cell). The ganglion was then processed for glyoxylic acid histofluorescence as described above. Dye-injected cells exhibit red fluorescence with the Leitz N2 filter cube (excitation filter 530-560 nm, mirror $580 \mathrm{~nm}$, barrier filter $580 \mathrm{~nm}$ ). The cell could then be checked for monoamine histofluorescence by switching to the $D$ filter cube, with minimal interference between the intracellular and monoamine labeling.

Transections. Isolated CNSs (abdominal, pedal, pleural, cerebral, and buccal ganglia) from adult Aplysia $(50-200 \mathrm{gm})$ were incubated at $18^{\circ} \mathrm{C}$ for 6-8 days in a solution of artificial seawater (in $\mathrm{mm}: 460 \mathrm{NaCl}, 10$ $\mathrm{KCl}, 11 \mathrm{CaCl}_{2}, 55 \mathrm{MgCl}_{2}$, buffered to $\mathrm{pH} 7.6$ with 10 HEPES) supplemented with glucose, essential and nonessential amino acids, vitamins; penicillin, and streptomycin (Eisenstadt et al., 1973). The bathing solution, which will be referred to as culture medium, was changed every other day. Each dish contained 2 nervous systems: in one the connectives between all the major ganglia were intact, and in the other the pleuralabdominal and cerebral-buccal connectives were transected (separating the abdominal and buccal ganglia from the other ganglia) at the beginning of the incubation period (Fig. $1 A$ ). At the end of the incubation period, the abdominal and buccal ganglia were processed for glyoxylic acid histofluorescence as described above.

Retrograde fluorescent labeling. Two different methods produced successful retrograde fluorescent labeling of neurons with cell bodies in the ring ganglia and axons projecting to the abdominal ganglion. The first method, which was used with animals weighing $0.5-5 \mathrm{gm}$, was to place the abdominal ganglion in a small, Vaseline-sealed well containing a $1 \%$ solution of lissamine rhodamine in culture medium, with the rest of the nervous system (connected to the abdominal ganglion by the pleural-abdominal connectives through the Vaseline seal) in normal culture medium (Fig. 1B). The second method, which was used with animals weighing 5-50 gm, was similar to the first except that the pleural-abdominal connectives were cut and their ends were placed in a well containing a $1 \%$ solution of propidium iodide in water. With either method, the preparation was then incubated at $18^{\circ} \mathrm{C}$ for $1-3 \mathrm{~d}$ with the culture medium outside the well changed daily. At the end of the incubation period, the ring ganglia were processed for glyoxylic acid histofluorescence as described above. Retrogradely labeled cells exhibit red fluorescence with the I eitz. N2 filter cube. The lissamine rhodamine method produced punctate labeling in the cytoplasm of the cell body, whereas the propodium iodide method produced labeling in the nucleus. The cell could then be checked for monoamine histofluorescence by switching to the D filter cube, with minimal interference between the retrograde and monoamine labeling.

\section{Results}

\section{Mapping monoamingergic neurons}

Abdominal ganglion. Figure $2 A$ shows an example of a glyoxylic acid-treated section through the dorsal side of the abdominal ganglion. Cells in the area of the RB cluster, which have been
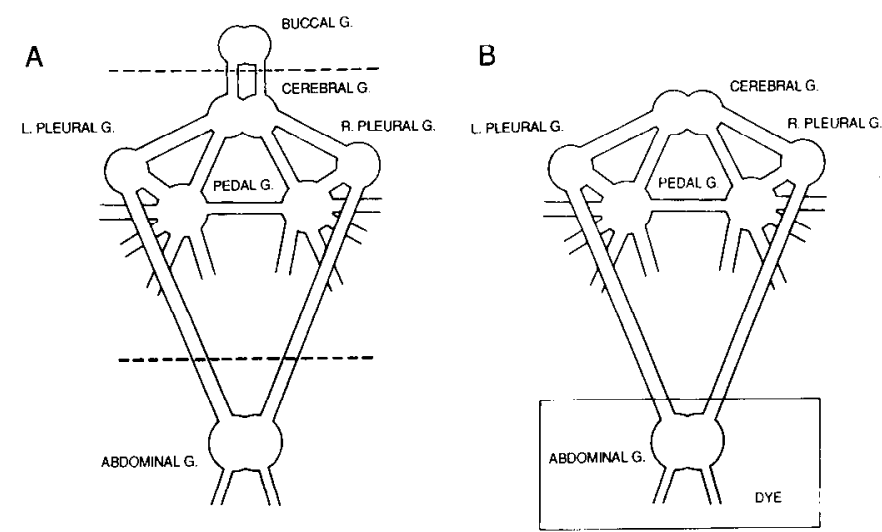

Figure 1. Methods. A, Diagram of nerve transection experiments. $B$, Diagram of retrograde fluorescent labeling experiments. See the text for details.

shown to be serotonergic by other methods (Eisenstadt et al., 1973; Liebeswar et al., 1975; Goldstein, 1984; Goldstein et al., 1984; Ono and McCaman, 1984; Kistler et al., 1985; Longley and Longley, 1986; Jahan-Parwar et al., 1987), fluoresce yellowgreen. The outlines of many nonfluorescing neurons, including the cholinergic neuron $\mathrm{R} 2$, are also visible. The cell bodies of virtually all of the neurons in the ganglion (and in the other central ganglia as well) are surrounded by a sparse network of 5-HT-fluorescing processes. These are seen at higher magnification in Figure $8 A$, which shows a section through the left ventral abdominal ganglion in the vicinity of the siphon sensory cells. A few neurons and/or blood vessels in the posterior region of the ganglion, sometimes including 5-HT-fluorescing neurons, are surrounded by a network of dopamine-fluorescing fibers, as illustrated in Figure $7 A_{2}$.

Figure 3 shows a serial reconstruction of all of the fluorescent neurons in a representative abdominal ganglion. For this purpose, the ganglion has been divided into 4 layers: dorsal surface, dorsal subsurface, ventral surface, and ventral subsurface. The dorsal layers are viewed from the dorsal side, and the ventral layers are viewed from the ventral side. $\mathrm{R} 2$ (which does not fluoresce) is shown for orientation. Abdominal ganglia from 5 adult animals were completely mapped in this manner, and abdominal ganglia from several more animals were examined more casually. There were consistently 3 groups of serotonergic neurons: a cluster on the right dorsal surface and subsurface of about 50 medium-sized $(75-150 \mu \mathrm{m})$ to small (less than $75 \mu \mathrm{m}$ ) cells; a cluster on the left dorsal subsurface extending to the ventral subsurface of about 25 medium to small cells; and a cluster on the right ventral surface of about 12 small cells. The exact locations and shapes of the clusters were somewhat variable. In addition, there were occasionally 1-5 medium-sized cells near the lateral edge of the left ventral (or dorsal) subsurface. There were not usually any dopamine cell bodies in the abdominal ganglion, but in some cases there was a single medium-sized dopamine cell in the cluster of serotonergic cells on the right dorsal surface.

Cerebral ganglia. Figure $2 B$ shows an example of a section through the dorsal side of the left and right cerebral ganglia, and Figure 4 shows a scrial reconstruction of representative ganglia. Cerebral ganglia from 3 adult animals $(50 \mathrm{gm})$ and 1 juvenile animal (5 gm) were completely mapped in this manner, and cerebral ganglia from several more animals were examined more 

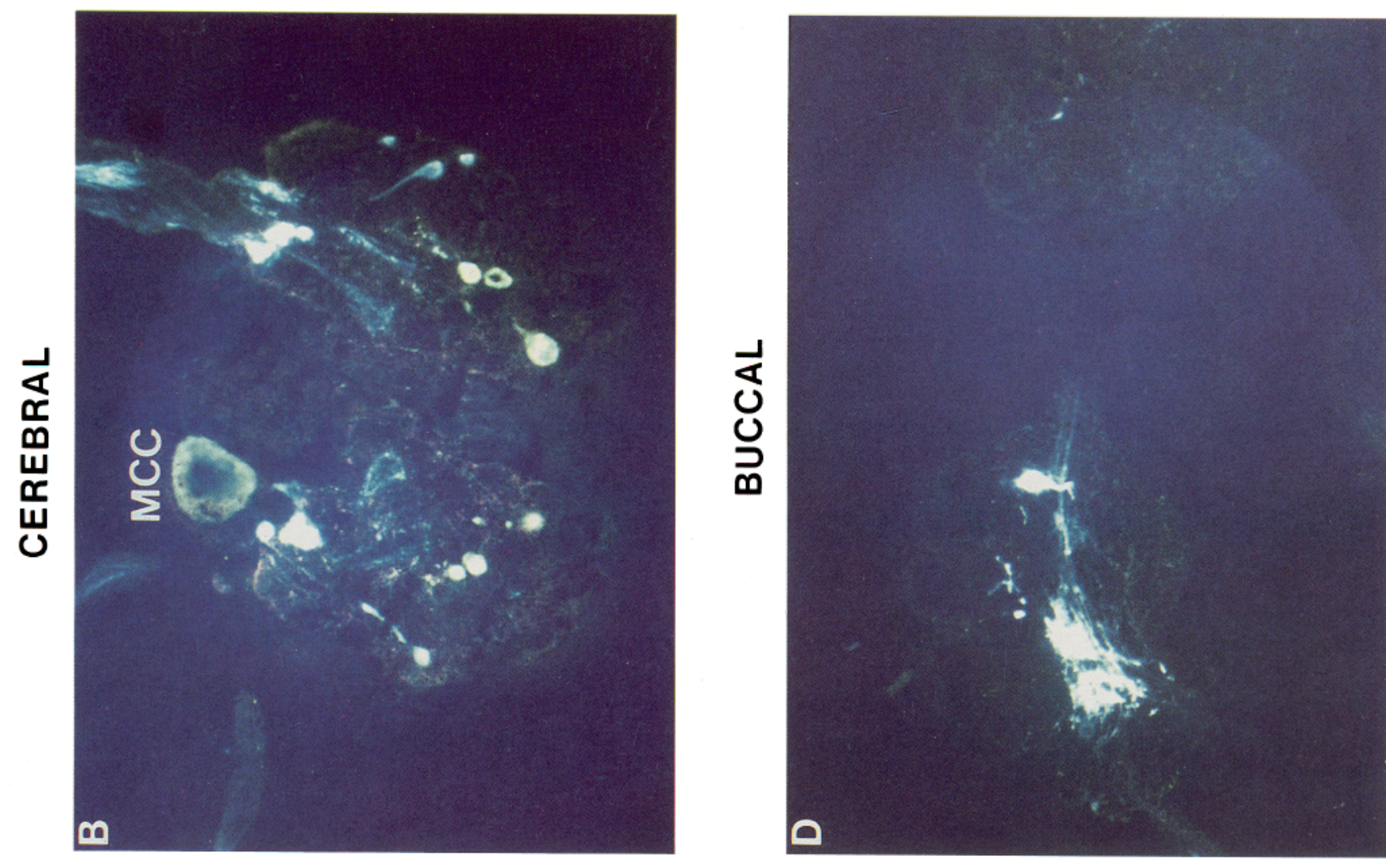

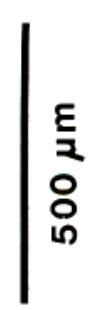
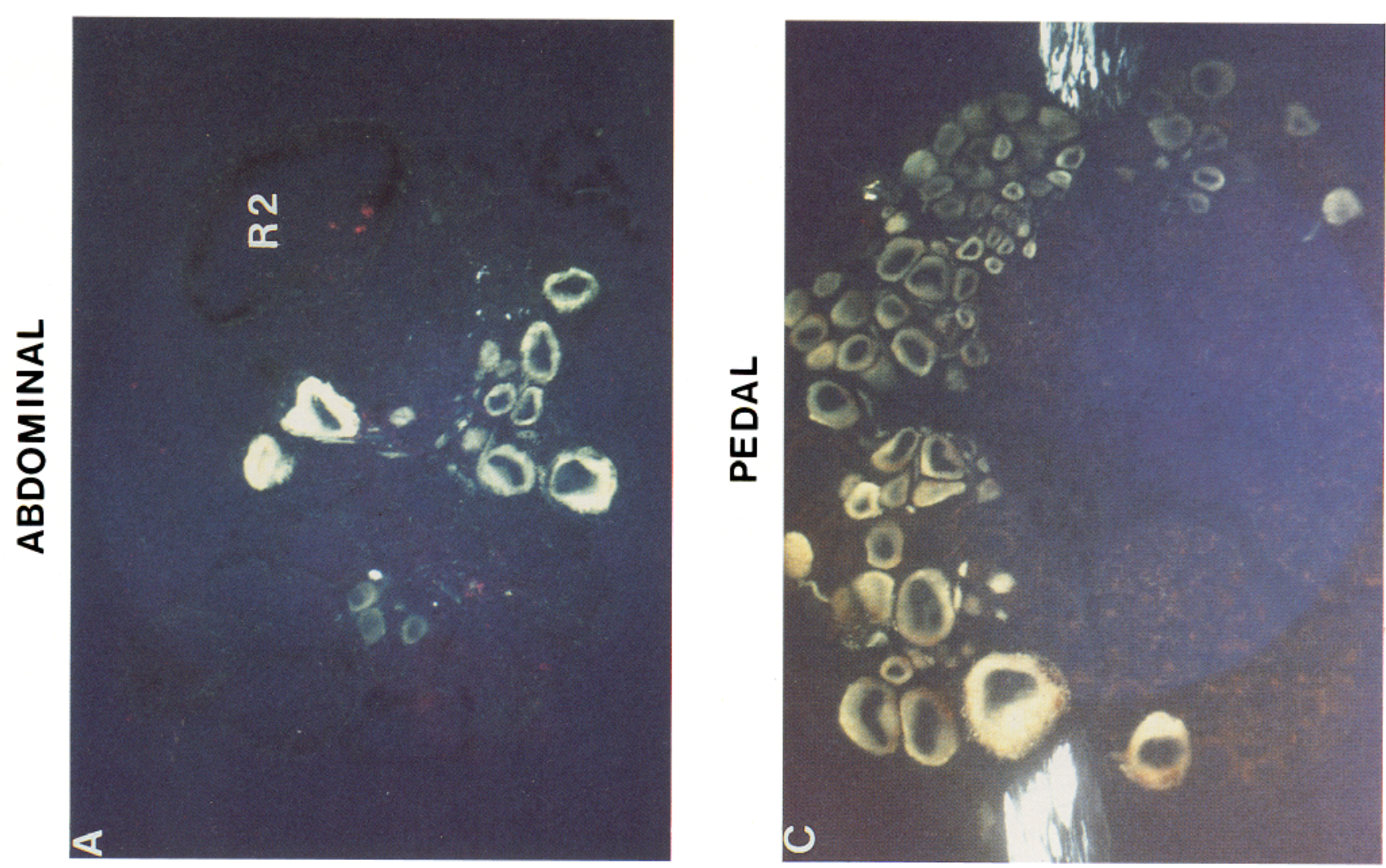


\section{ABDOMINAL}

DORSAL SURFACE

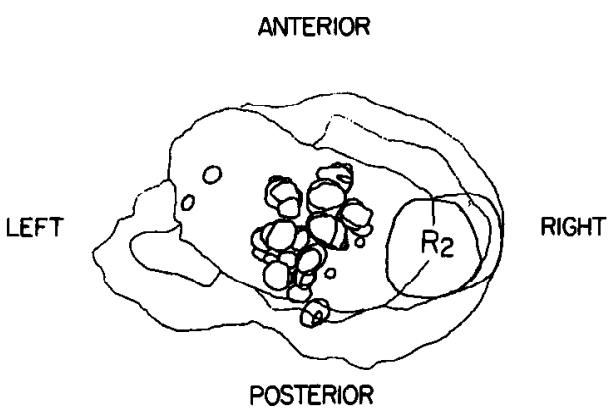

DORSAL SUBSURFACE

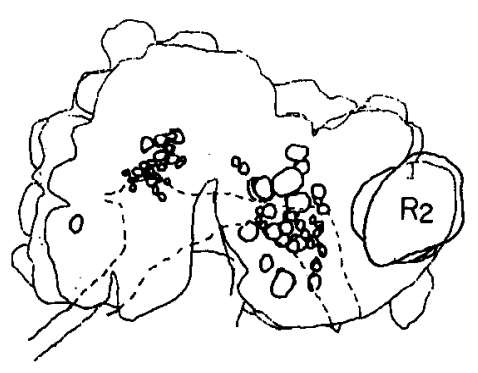

VENTRAL SURFACE

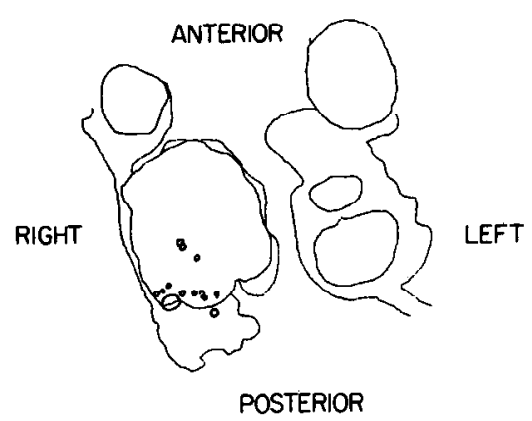

VENTRAL SUBSURFACE

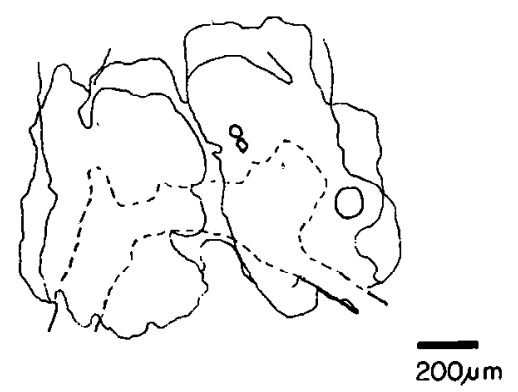

Figure 3. Reconstruction of the abdominal ganglion from serial sections showing the outlines of monoaminergic cells. In this and the following figures, open circles indicate 5-HT fluorescing cells and filled circles indicate catecholamine fluorescing cells. R2, which is not monoaminergic, is shown for orientation. The cell outlines from every second section and the ganglion outline from every fourth section are shown. Section thickness was $30 \mu \mathrm{m}$. The outline of the central neuropil is indicated by a dashed line. casually. In addition to the serotonergic metacerebral cells (MCCs), there were consistently 2 groups of serotonergic neurons in each ganglion: a cluster on the posterior dorsal surface of about 5 medium-sized cells; and a cluster on the anterior dorsal and ventral subsurfaces of 25-30 medium to small cells.

There were also consistently 3 groups of dopaminergic neurons in each cerebral ganglion: a cluster on the anterior dorsal surface and subsurface of up to 10 small cells; a cluster on the lateral dorsal surface and subsurface of about 5 small cells; and a cluster on the posterior ventral surface of 5-15 small cells. There was a tendency for the clusters of dopamine cells in the left ganglion to have more cells than those in the right, but I did not map ganglia from enough animals to determine whether this was a reliable difference. In addition to these clusters of small cells, there were occasionally 1-2 medium-sized dopamine cells in the cluster of serotonergic cells on the anterior, dorsal, and ventral subsurfaces.

The cerebral ganglia from 1 juvenile animal showed a similar general pattern, but had fewer serotonergic and dopaminergic neurons on each cluster. The total number of monoaminergic cells was approximately $50 \%$ of that seen in adults.

Pedal and pleural ganglia. No serotonergic or dopaminergic cell bodies were observed in the pleural ganglia. Figure $2 C$ shows an example of a section through the left pedal ganglion, and Figure 5 shows a serial reconstruction of a representative ganglion. Pedal ganglia from 3 adult animals and 1 juvenile animal were completely mapped in this manner, and pedal ganglia from several more animals were examined more casually. There were consistently 3 groups of serotonergic neurons in each pedal ganglion: a cluster extending from the posterior-dorsal surface to the posterior-ventral surface of about 200 large $(>150 \mu \mathrm{m})$ to small cells; a cluster on the anterior-dorsal surface of about 15 large to medium cells; and a cluster on the anterior-ventral surface of about 10 large to medium cells.

The number and position of dopamine cells was more variable, but there was usually a cluster on the dorsal surface of 315 medium- to small-sized cells, and there was occasionally a cluster on the ventral subsurface of 1-3 medium-sized cells. There was not any obvious difference between the left and right pedal ganglia in either 5-HT or dopamine cells, but I did not examine enough ganglia to detect differences in details.

The pedal ganglia from 1 juvenile animal showed a similar general pattern, but had fewer serotonergic and dopaminergic neurons in each cluster. The total number of monoaminergic cells was approximately $60 \%$ of that seen in adults.

Buccal ganglia. Figure $2 D$ shows an example of a section through the left and right buccal ganglia, and Figure 6 shows a serial reconstruction of the ganglia. The buccal ganglia from 1 adult animal were reconstructed in this manner, and buccal ganglia from several more animals were examined more casually. No serotonergic cell bodies are observed in the buccal ganglia. Three to five medium- to small-sized dopamine cells are found

Figure 2. Examples of glyoxylic acid histofluorescence in Aplysia ganglia. Serotonergic cells fluoresce yellow-green and catecholaminergic cells fluoresce blue. $A$, Abdominal ganglion. $B$, Cerebral ganglia. $C$, Pedal ganglion. $D$, Buccal ganglia. 
DORSAL SURFACE

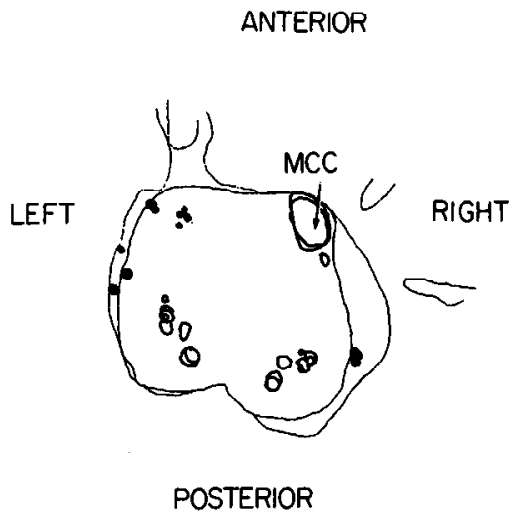

DORSAL SUBSURFACE

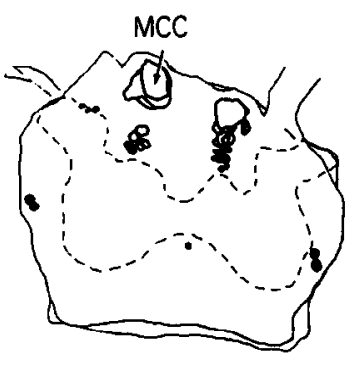

VENTRAL SURFACE

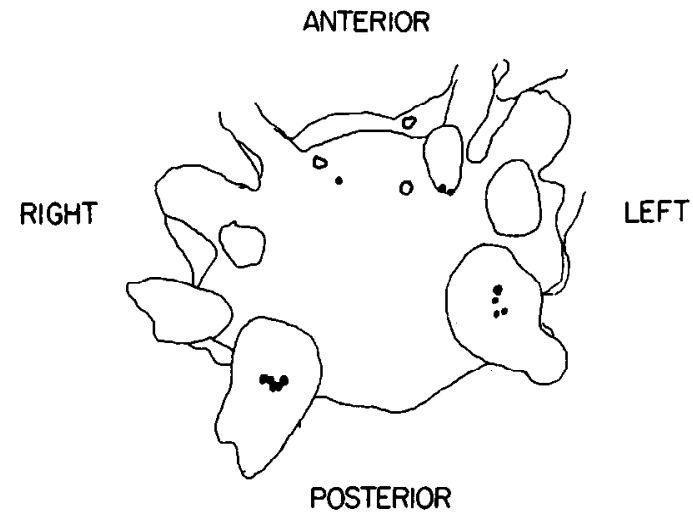

VENTRAL SUBSURFACE

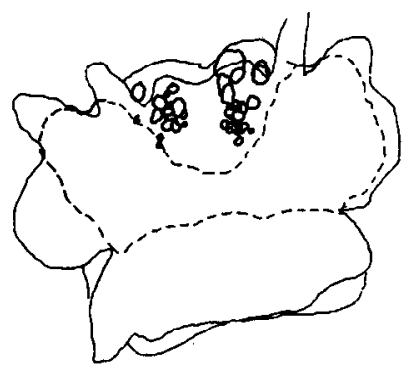

Figure 4. Reconstruction of the cemonoaminergic cells. See the legend of Figure 3. MCC indicates the metacerebral cells. along the midline of each ganglion. Since I reconstructed the buccal ganglia from only 1 animal, I do not know whether the number and position of these cells is variable.

Summary. Table 1 summarizes the results of these mapping studies. A total of about 90 serotonergic cells was found in the abdominal ganglion, about 35 in each cerebral ganglion, and more than 200 in each pedal ganglion. No serotonergic cells were found in the pleural or buccal ganglia. There were also about 20 dopaminergic neurons in each cerebral ganglion, 5-15 in each pedal ganglion, and about 4 in each buccal ganglion. One dopamine cell was occasionally found in the abdominal ganglion, and none were found in the pleural ganglia.

\section{Intracellular fluorescent labeling}

The results described above provide a map of the distribution of monoaminergic neurons in the nervous system of Aplysia, but they do not show whether individual identified neurons are monoaminergic except for large cells that can be identified by visual criteria alone, such as R2 and the MCCs. To tell whether smaller cells are monoaminergic, it is necessary to identify them electrophysiologically and label them with an intracellular dye compatible with the glyoxylic acid histofliurescence method. I tried a number of dyes and found one, lissamine rhodamine, that was suitable for this purpose. Figure 7 illustrates this method with 2 identified cells in the abdominal ganglion, an RB cell and an $\mathrm{L} 29$ cell.
RB cells have previously been shown to be serotonergic by several methods (Eisenstadt et al., 1973; Liebeswar et al., 1975; Tritt et al., 1983; Goldstein, 1984; Goldstein et al., 1984; Ono and McCaman, 1984; Kistler et al., 1985; Longley and Longley, 1986; Jahan-Parwar et al., 1987; Salimova et al., 1987). Cells in the region of the RB cluster (the posterior right dorsal hemiganglion) show 5-HT histofluorescence (Figs. $2 A$ and 3). As a more definitive test, an RB cell identified electrophysiologically by the criteria of Frazier et al. (1967) was injected iontophoretically with lissamine rhodamine and the ganglion was processed for glyoxylic acid histofluorescence. As shown in Figure $7 A_{t}$, the injected cell fluoresces red when viewed with a Leitz N2 filter cube. Figure $7 A_{2}$ shows the same section viewed with a $\mathrm{D}$ filter cube for monoamine histofluorescence. The injected cell fluoresces yellowish, indicating that it contains 5-HT.

L29 refers to a group of several neurons in the abdominal ganglion, stimulation of which produces presynaptic facilitation of the siphon sensory cells (Hawkins, 1981; Hawkins et al., 1981b). Data from morphological studies and experiments on 5-HT uptake suggested that those neurons might be serotonergic (Bailey et al., 1981, 1983). However, immunocytochemical studies indicated that the L29 neurons do not contain 5-HT (Ono and McCaman, 1984; Kistler et al., 1985; Longley and Longley, 1986). Results with the glyoxylic acid histofluorescence method provide additional evidence that the L29 cells are not serotonergic. First, no serotonergic cells are found in the ante- 


\section{L.PEDAL}

DORSAL SURFACE

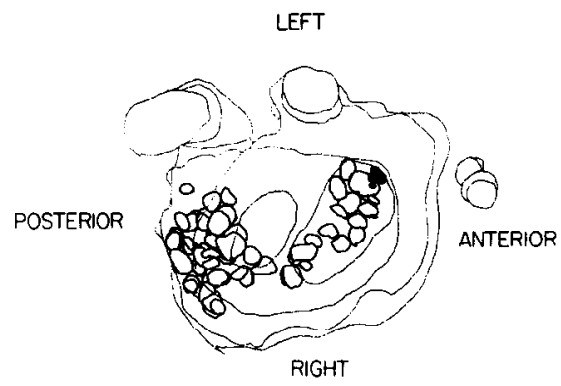

DORSAL SUBSURFACE

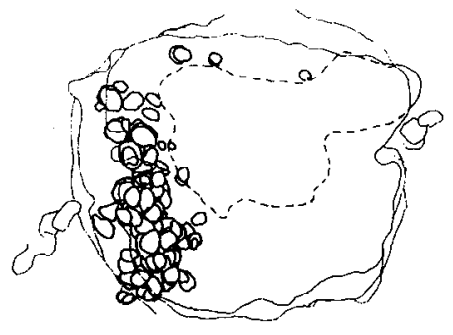

VENTRAL SURFACE

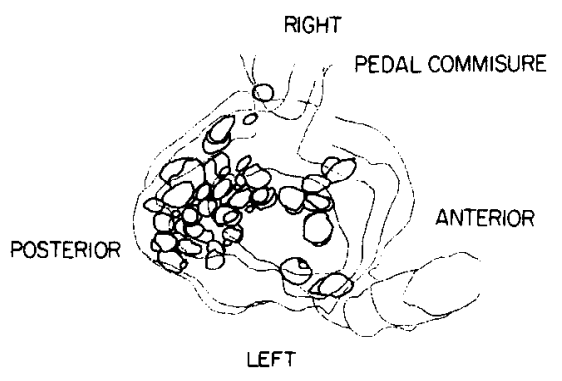

LEFT

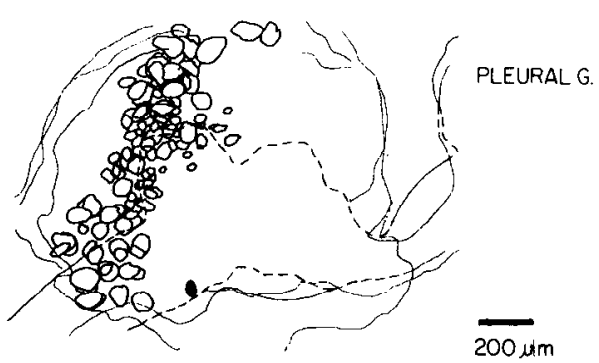

Figure 5. Reconstruction of the left pedal ganglion showing the outlines of monoaminergic cells. See the legend of Figure 3. rior, left ventral region of the abdominal ganglion (Fig. 3), which is where the L29 cells are usually located (Hawkins et al., 1981a). As a more definitive test, an L29 neuron identified electrophysiologically by the criteria of Hawkins et al. (1981a) was injected with lissamine rhodamine (Fig. $7 B_{l}$ ). As shown in Figure $7 B_{2}$, the injected $L 29$ neuron shows no monoamine histofluorescence, indicating that it is not serotonergic. Since monoamine histofluorescence is often brighter in the axons than in the cell bodies of neurons, I also injected identified L29 neurons with lissamine rhodamine and left the ganglion in organ culture overnight to label the axon, and again saw no corresponding 5-HT histofluorescence.

\section{Transection experiments}

The finding that the L29 cells are not serotonergic prompled a further search for serotonergic facilitator neurons. I first tested cells in areas of the abdominal ganglion where the glyoxylic acid method showed that serotonergic cells are located (Fig. 3). Stimulating cells in those regions has not produced facilitation of PSPs from siphon sensory cells, although it is possible that the critical cells have been missed. Alternatively, serotonergic facilitator neurons may have their cell bodies in other ganglia and send processes to the abdominal ganglion. I attempted to test this possibility with the transection experiments illustrated in Figure $1 A$.

The abdominal ganglion was left in organ culture for approximately 1 week, either connected to the ring ganglia (pedal, pleural, and cerebral) or separated from them by transecting the pleural-abdominal connectives. If serotonergic processes in the abdominal ganglion come from cell bodies in the other ganglia, they should lose their transmitter (due either to degeneration or to depletion) more rapidly when the abdominal ganglion is isolated than when it is connected to the other ganglia. If, however, those processes come from cell bodies in the abdominal gan-

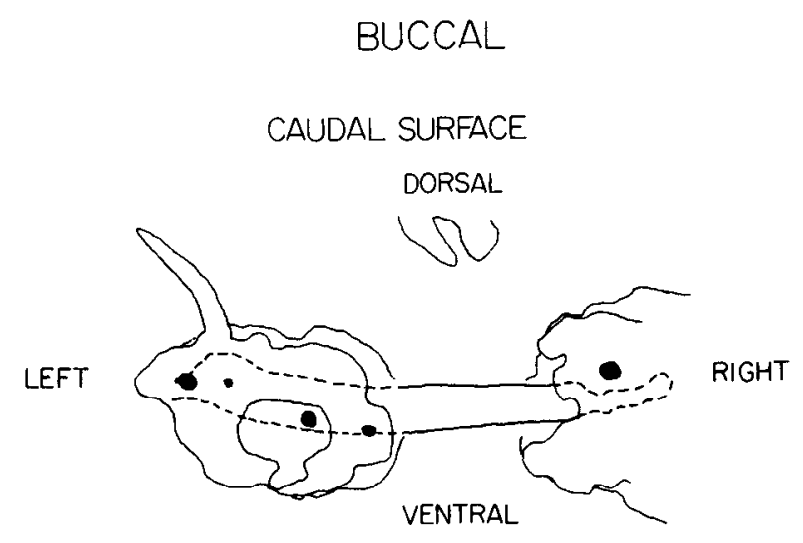

ROSTRAL SURFACE

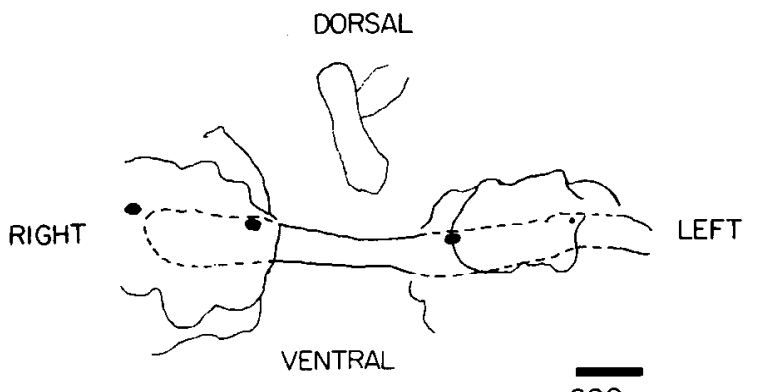

$200 \mu \mathrm{m}$

Figure 6. Reconstruction of the buccal ganglia showing the outlines of monoaminergic cells. See the legend of Figure 3. 

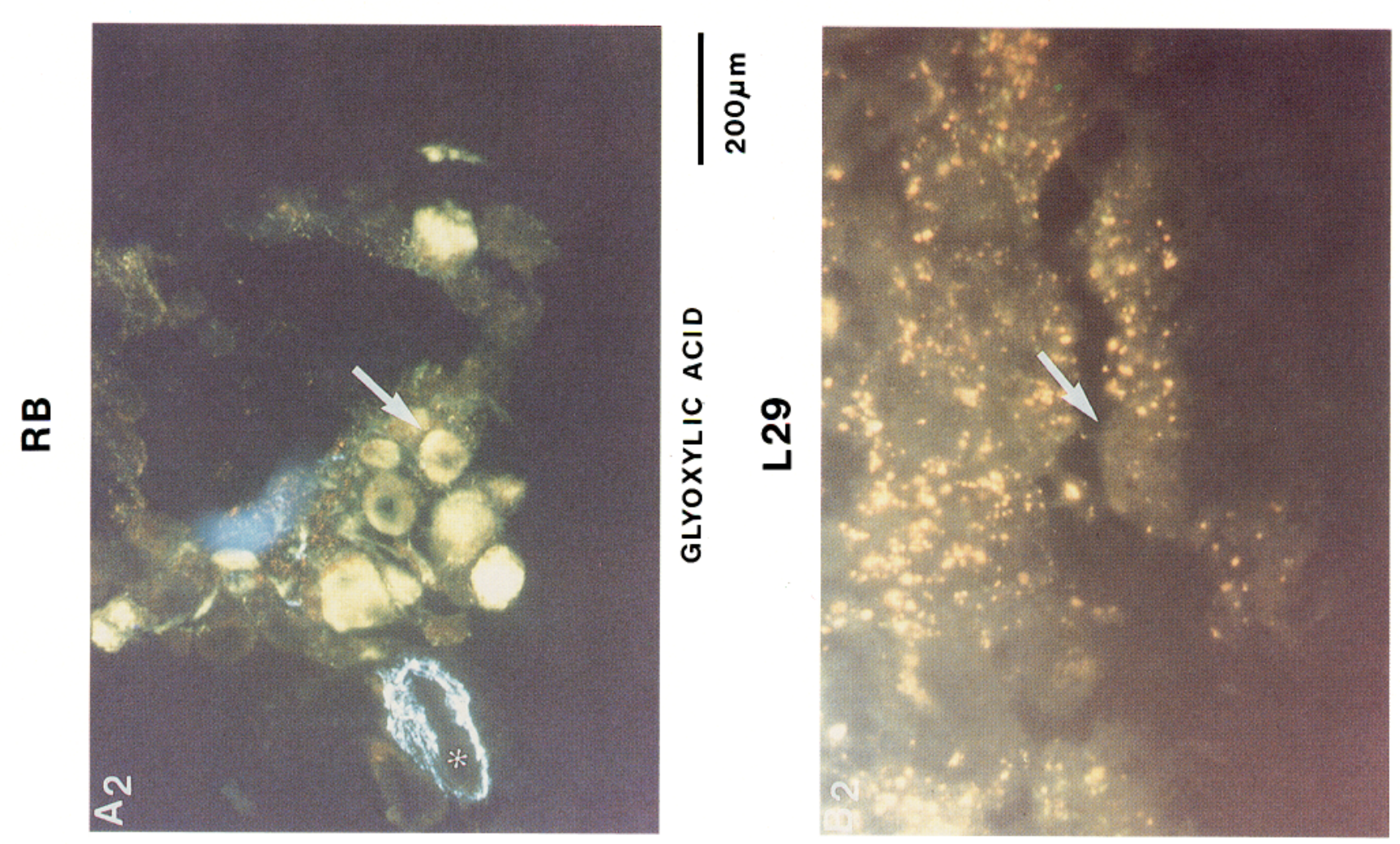

|
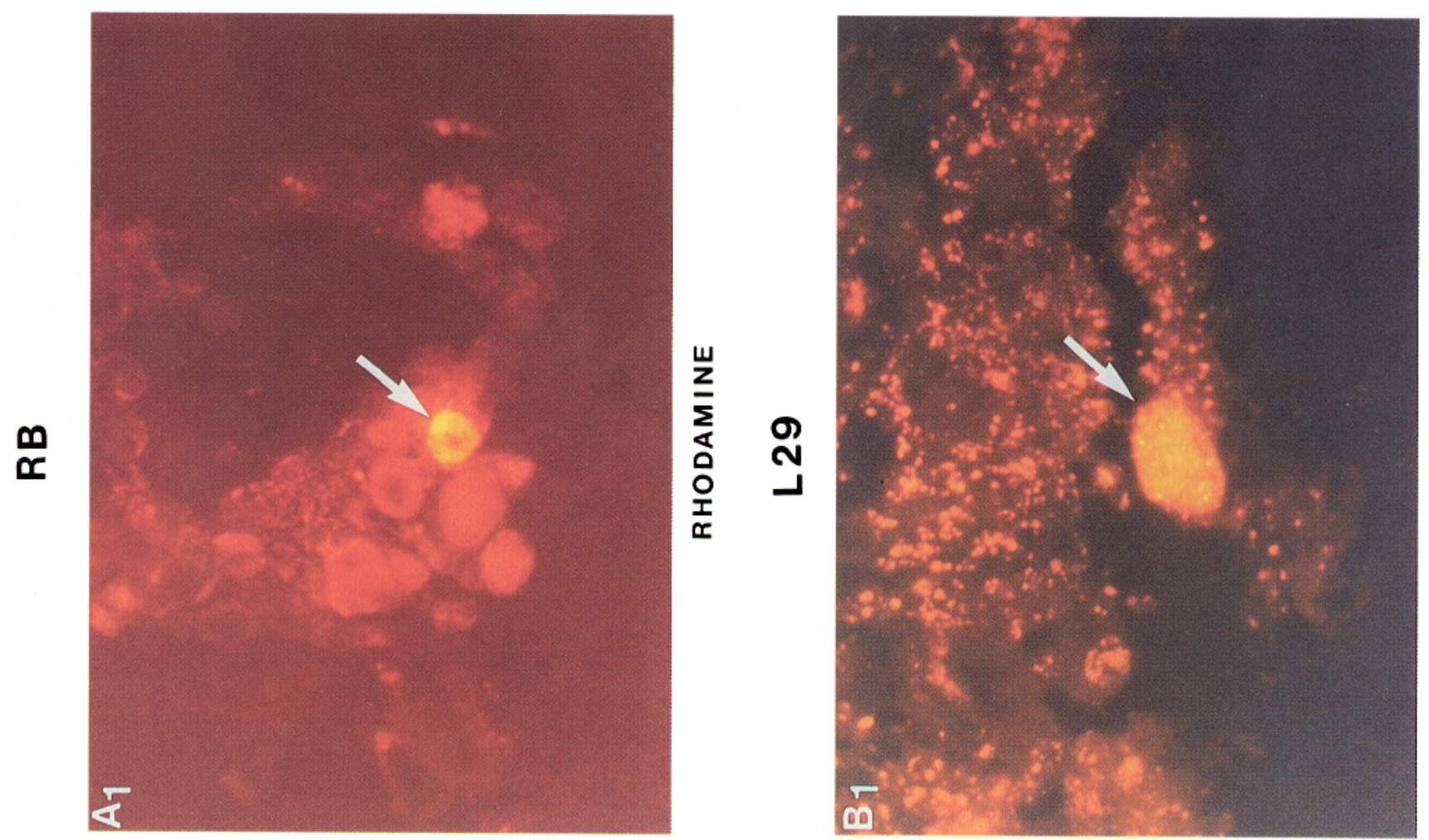

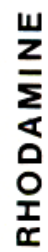




\section{CONNECTED}

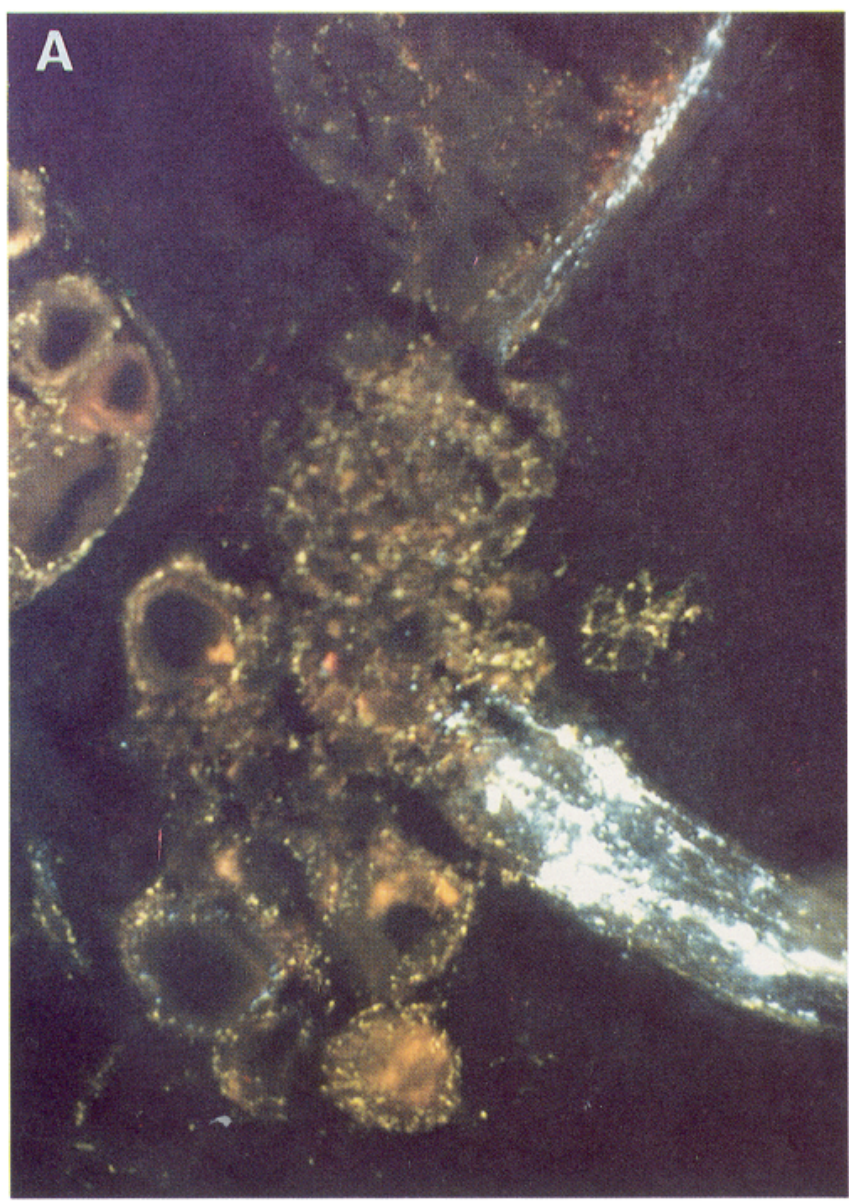

ISOLATED

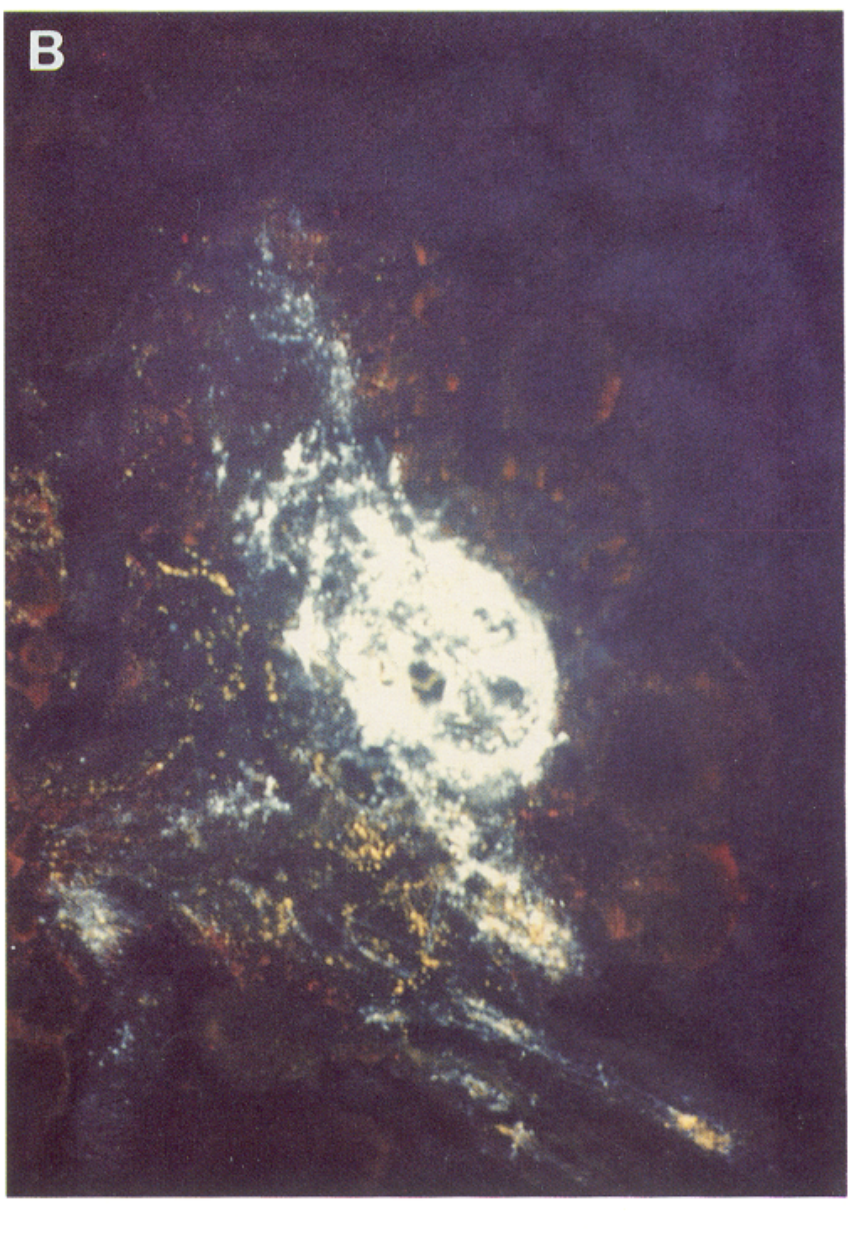

$200 \mu \mathrm{m}$

Figure 8. Examples of results from the nerve transection experiments. A, A glyoxylic acid treated section from an abdominal ganglion that had been left connected to the ring ganglia for 6 days in organ culture. $B$, A similar section from an abdominal ganglion that had been isolated from the ring. There is much less perisomatic histofluorescence in the isolated ganglion than in the connected ganglion.

glion, transmitter loss should be approximately equal in the 2 cases.

Figure 8 shows glyoxylic acid treated sections from the region of the siphon sensory cells in 2 abdominal ganglia. Figure $8 \mathrm{~A}$ is from an abdominal ganglion that had been left connected to the ring ganglia for 6 days in organ culture. The glyoxylic acid histofluorescence is similar to that in a freshly dissected ganglion; in particular, there is a clear network of serotonergic processes around the cell bodies of most of the neurons. Figure $8 B$ is from an abdominal ganglion that had been separated from the ring ganglia for the same amount of time, in the same culture dish as the ganglion shown in part $A$. The fluorescence of the serotonergic processes around the cell bodies is greatly reduced or absent. This was true throughout the abdominal ganglion, except for a restricted area in the anterior medial region of the ganglion. By contrast, the fluorescence of serotonergic cell bodies and axons, as well as dopaminergic processes, was not obviously affected by transecting the pleural-abdominal connectives. Similar results were obtained from 4 of 5 pairs of abdominal ganglia treated in this manner; in the fifth pair, the fluorescence of serotonergic processes was reduced in both ganglia. As a check on the method, similar results were also obtained from 5 pairs of buccal ganglia, which contain no serotonergic cell bodies: 5-HT histofluorescence was present in the connected, but not the isolated, buccal ganglia.

These results suggest that most of the perisomatic serotonergic

\section{$\leftarrow$}

Figure 7. Combined intracellular labeling with lissamine rhodamine and glyoxylic acid histofluorescence. $A_{l}$, An RB cell that had been injected with lissamine rhodamine, viewed with rhodamine filters. $A_{2}$, The same section viewed with histofluorescence filters. The injected cell (arrow) shows 5-HT histofluorescence. ${ }^{*}$ indicates a nonfluorescing neuron or blood vessel surrounded by a dense network of catecholamine processes. $B_{l}$, An L29 cell injected with lissamine rhodamine. $B_{2}$, The same section viewed with histofluorescence filters. The injected cell (arrow) shows no monoamine histofluorescence. 


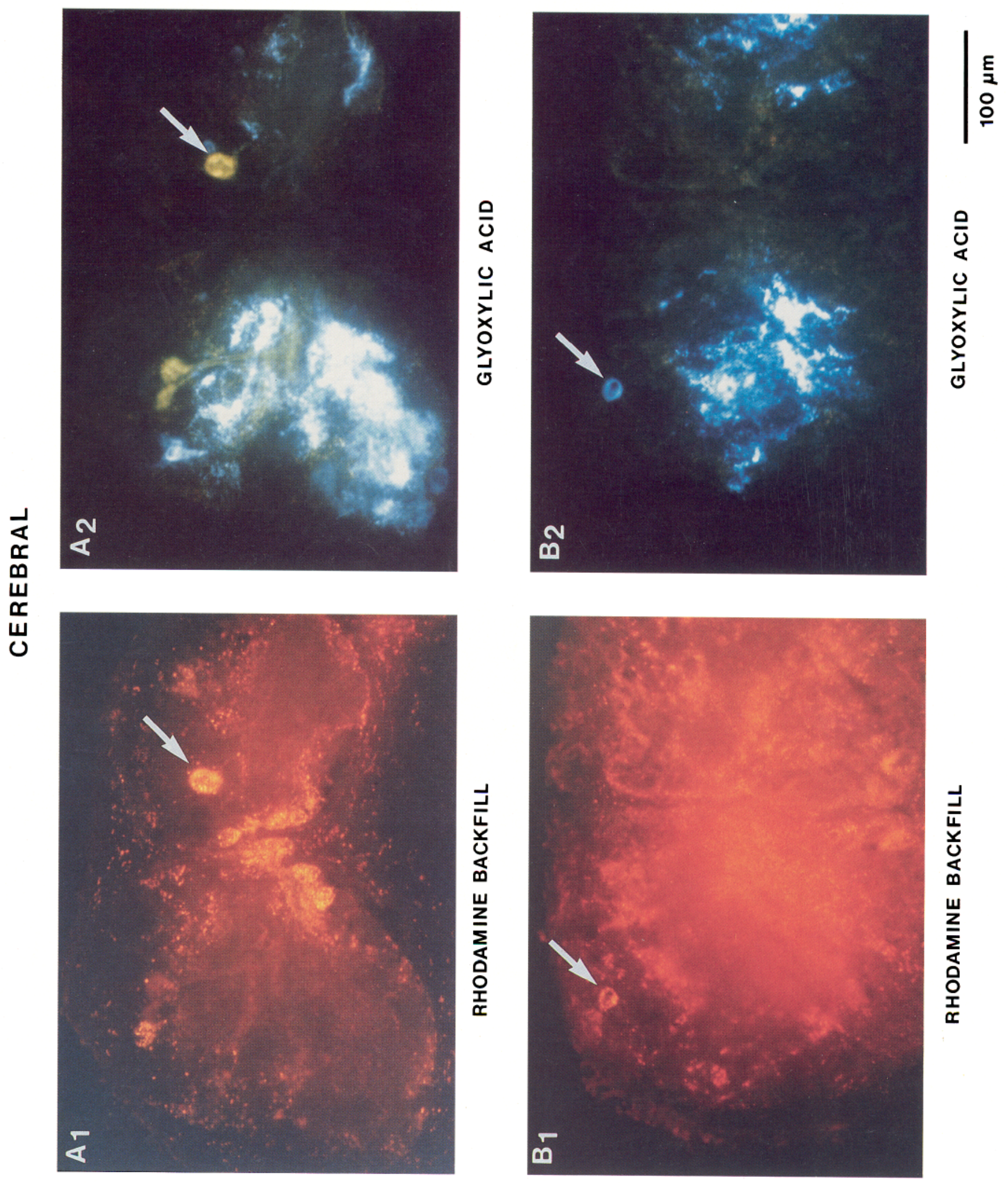


Table 1. Approximate number of monoaminergic neurons in adult Aplysia ganglia

\begin{tabular}{lcc} 
Ganglion & 5-HT cells & DA cells \\
\hline Abdominal & 90 & $(1)$ \\
Each cerebral & 35 & 20 \\
Each pedal & $>200$ & 10 \\
Each pleural & 0 & 0 \\
Each buccal & 0 & 4 \\
\hline
\end{tabular}

processes in the abdominal ganglion come from neurons in the ring ganglia. I have attempted to use the transection technique to determine which ganglion they come from by leaving the abdominal ganglion connected to either the cerebral or the pedal ganglia, but the results have not been as clear. This ambiguity suggests that the scrotoncrgic processes in the abdominal ganglion may come from more than 1 ganglion in the ring.

\section{Retrograde fluorescent labeling}

The results of the transection experiments described above suggested that there may be serotonergic facilitator neurons that have their cell bodies in the ring ganglia and send axons to the abdominal ganglion. Since there are at least 500 serotonergic neurons in the ring ganglia (Table 1), however, it was impractical to test all of them. I therefore combined glyoxylic acid histofluorescence with retrograde fluorescent labeling to identify that subset of serotonergic neurons in the ring ganglia that send an axon to the abdominal ganglion.

Figure $9 A$ shows an example of a double-labeled serotonergic cell in the cerebral ganglia. In Figure $9 A_{l}$, the section is viewed with the $\mathrm{N} 2$ filter cube, showing retrograde labeling from the abdominal ganglion with lissamine rhodamine. In Figure $9 A_{2}$, the same section is viewed with the $D$ filter cube, showing glyoxylic acid labeling of monoamines. The arrows identify a neuron that is labeled by both methods. This technique has been used to locate approximately 12 bilaterally symmetrical monoaminergic neurons in the ring ganglia that send axons to the abdominal ganglion (Fig. 10). On each side, there is a medium-sized serotonergic neuron in the $B$ cluster of the cerebral ganglion (this cell is shown in Fig. 9A), a large serotonergic neuron on the anterior edge of the pedal ganglion, and a group of 3 or 4 smaller serotonergic neurons on the posterior side of the pedal ganglion. There is also a smallish dopaminergic neuron on the anterior edge of the cerebral ganglion (this cell is shown in Fig. 9B). Each of these neurons has been clearly double-labeled in more than 1 experiment. Since the results are somewhat variable from experiment to experiment (particularly for the retrograde labeling), there may be additional neurons which have been missed.

\section{Discussion}

\section{Mapping monoaminergic neurons by glyoxylic acid} histofluorescence

This paper describes the first systematic mapping of monoaminergic neurons in $A$. californica by the glyoxylic acid histoflu-

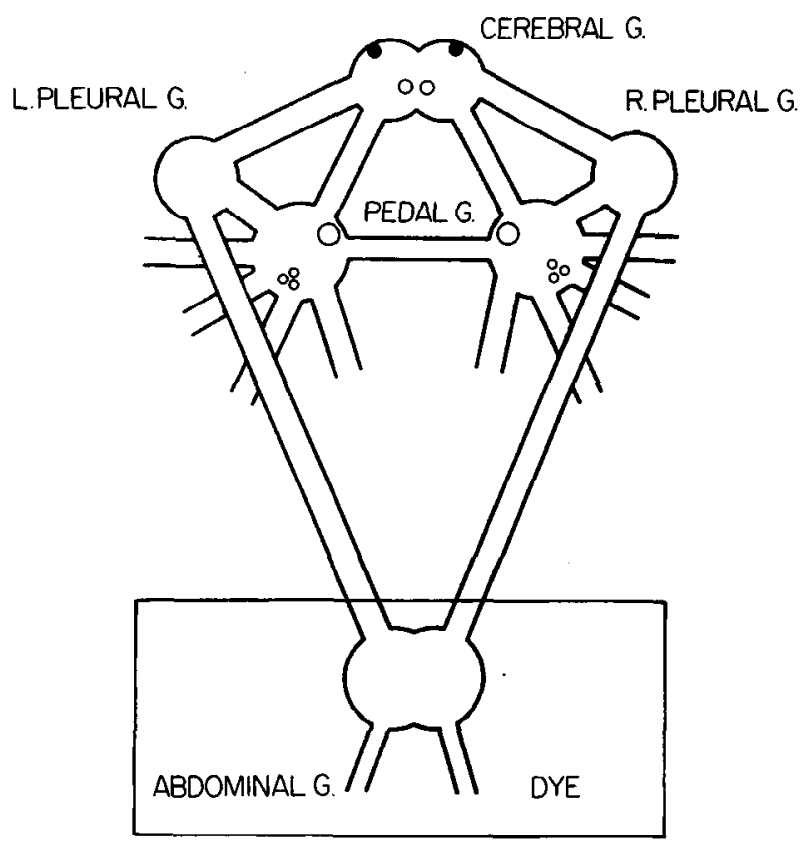

Figure 10. Diagram of neurons in the ring ganglia that show both monoamine histofluorescence and retrograde fluorescent labeling from the abdominal ganglion. Open circles $=5$-HT fluorescing neurons; filled circles $=$ catecholamine-fluorescing neurons.

orescence technique. Several previous papers have described glyoxylic acid histofluorescence in Aplysia with basically similar results (Tritt et al., 1983; Goldstein, 1984; Salimova et al., 1987; Rathouz and Kirk, 1988; Goldstein and Schwartz, 1989). However, only one of those studies (Salimova et al., 1987) provided a systematic mapping, and that was for Aplysia depilans. There are several differences in details between my results and those of Salimova et al. (1987), which could be due to the different species used or differences in technique. Although I usually used a somewhat different glyoxylic acid method (Bolstad et al., 1979; Barber, 1982), which produced better labeling, I still got different results than Salimova et al. (1987) when I used their method (de la Torre and Surgeon, 1976). Thus, it seems likely that there are species differences between $A$. californica and $A$. depilans.

The distribution of serotonergic neurons in $A$. californica has previously been examined by immunocytochemistry (Goldstein, 1984; Goldstein et al., 1984; Ono and McCaman, 1984; Kistler et al., 1985; Longley and Longley, 1986) and 5,7-DHT staining (Jahan-Parwar et al., 1987). There is general agreement between my results with the glyoxylic acid method and results with these other methods concerning the major cell groups that are 5-HT positive. In addition, my results also agree with immunocytochemical results on identified RB and L,29 cells (Kistler et al., 1985) and with biochemical assays of 5-HT content or synthesis in RB, R2, and MCCs (Weinreich et al., 1973; Eisenstadt et al., 1973; Liebeswar et al., 1975; Ono and McCaman, 1984). This agreement between different techniques tends to support the specificity of each of them.

Figure 9. Combined retrograde labeling with lissamine rhodamine and glyoxylic acid histofluorescence. $A_{i}$, A section through the cerebral ganglia viewed with rhodamine filters, showing several neurons with retrograde labeling from the abdominal ganglion. $A_{z}$, The same section viewed with histofluorescence filters. One neuron (arrow) shows both retrograde labeling and 5-HT histofluorescence. $B_{i}$, Another section through the cerebral ganglia viewed with rhodamine filters. $B_{2}$, The same section viewed with histofluorescence filters, showing a catecholamine fluorescing neuron (arrow) that also backfilled from the abdominal ganglion. 
The major differences between these different studies have to do with the number of cells observed in each of the 5-HT positive cell groups. For example, the number of serotonergic cells reported in the left abdominal ganglion varies from 1 or 2 (Ono and McCaman, 1984; Longley and Longley, 1986; Salimova et al., 1987) to 20 or 30 (Kistler et al., 1985; Jahan-Parwar et al., 1987; and the present study). This study shows more 5-HTpositive cells than most of the previous studies. These differences in number of cells do not correlate with the type of assay [e.g., Ono and McCaman (1984), Longley and Longley (1986) and Kistler et al. (1985), all used immunocytochemistry, and Salimova et al. (1987) and the present study used glyoxylic acid] and thus are probably not due to differences in the inherent sensitivity or specificity of the assays. Rather, this study probably revealed more positive cells because it involved reconstruction of the ganglia from serial sections. This technique makes it possible to count cells accurately in the interior as well as on the surface of mature ganglia. Such counting showed that there is a substantial increase (between 50 and 100\%) in the number of monoamine-positive cells between the late juvenile $(5 \mathrm{gm})$ and adult (50 gm) stages of development, in agreement with previous reports of increases in the number of both monoaminergic and nonmonoaminergic neurons (Goldstein, 1984; Goldstein et al., 1984; Kistler et al., 1985; Cash and Carew, 1989; Goldstein and Schwartz, 1989).

An advantage of the glyoxylic acid method is that it permits visualization of catecholamines as well as 5-HT. In basic agreement with previous studies (Tritt et al., 1983; Goldstein, 1984; Salimova et al., 1987; Rathouz and Kirk, 1988; Goldstein and Schwartz, 1989), there were consistently catecholamine (presumably dopamine) neurons in the cerebral, pedal, and buccal ganglia, and occasionally in the abdominal ganglion. There was also a dense network of catecholamine processes enveloping some neurons and/or blood vessels in the posterior part of the abdominal ganglion.

Although the same cell groups were consistently monoaminepositive from animal to animal, there was considerable variation in the position and shape of the cell groups and the number of cells they contained. In addition, individual neurons sometimes appeared outside of the major groups. For example, there were sometimes, but not always, from 1 to 5 serotonergic cells on the lateral margin of the left abdominal ganglion, and a single catecholamine neuron on the right dorsal surface of the abdominal ganglion. This variability could be apparent (due, for example, to variability in the threshold of detection of the assay) or it could be real. If it is real, individual neurons could be strays from the major groups, or they could represent anomalies in transmitter expression. In the case of the catecholamine cells, the latter possibility seems more likely, since such cells always appeared within clusters of similar-sized serotonergic cells.

\section{LRB: An intracellular and retrograde fluorescent label compatible with glyoxylic acid histofluorescence}

To test whether electrophysiologically identified neurons show glyoxylic acid histofluorescence, it is necessary to label the cells with an intracellular marker compatible with the glyoxylic acid method. Conventional markers such as fast green or horseradish peroxidase tend to obscure the histofluorescence. The fluorescent dye Lucifer yellow is also not suitable because its excitation and emission characteristics are similar to those of 5-HT histofluorescence. I therefore searched for another fluorescent dye that is easy to inject but has different excitation and emission characteristics, so that it can be distinguished from serotonin histofluorescence. I tried a number of rhodamine dyes and found one, LRB, that is suitable for this purpose. LRB had previously been used by Simpson et al. (1977) to examine dye coupling between salivary gland cells, but I have not observed dye coupling in Aplysia neurons. LRB is also suitable as a second intracellular dye in conjunction with Lucifer yellow (Hawkins and Schacher, 1989). LRB is generally comparable to Lucifer yellow as an intracellular dye: it is highly fluorescent, is easily injected either by iontophoresis or by pressure, quickly spreads into the processes of the cell, and does not leak out or appear to be toxic for up to $24 \mathrm{hr}$. Its one drawback is that it does not fix with conventional paraformaldehyde fixation procedures and is therefore limited to use either in living tissue or in cyrostatsectioned material.

LRB also turned out to be useful as a retrograde fluorescent dye compatible with glyoxylic acid histofluorescence. It works best when it is applied to the terminals (rather than the cut axon) of a neuron and labels cell bodies a relatively long distance (centimeters) away. The punctate appearance of the labeling in the cell body suggests that the dye is carried by retrograde transport mechanisms. I also had success with propodium iodide as a retrograde fluorescent marker compatible with glyoxylic acid histofluorescence (Van der Kooy and Wise, 1980; Wieland et al., 1983). The 2 retrograde labeling methods produced similar results. Propodium iodide worked best when applied to the cut axon of a neuron and did not spread as far as LRB. A number of other fluorescent dyes that are good retrograde markers in vertebrates, including Fluorogold, Nuclear yellow, True blue, DAPI, Primulin, Bisbenzimide, Evans blue, and Doxorubicin, did not label cell bodies when applied to cut axons in Aplysia.

\section{Localization of serotonergic facilitator neurons by nerve transections and retrograde fluorescent labeling}

One of the more striking results from both immunofluorescence and glyoxylic acid histofluorescence studies is the existence of a sparse network of serotonergic processes around the cell bodies of almost all neurons in the CNS. The MCCs can evidently account for many of these perisomatic processes in the buccal ganglia (Shkolnik and Schwartz, 1980); it would be interesting to know the origin of these processes in other ganglia, and what their functional role is. The nerve transection experiments described in this paper suggest that most of the perisomatic serotonergic processes in the abdominal ganglion, including those around the siphon sensory neurons, come from neurons whose cell bodies are located in the cerebral or pedal ganglia. These results do not rule out the existence of serotonergic facilitator neurons in the abdominal ganglion, since such neurons might contact the sensory neurons in the neuropil. Nonetheless, these experiments provided the motivation to search in the ring ganglia for serotonergic facilitators.

The combination of retrograde fluorescent labeling and glyoxylic acid histofluorescence made it possible to locate a small number of serotonergic neurons in the ring ganglia that send axons to the abdominal ganglion and are therefore potential facilitators. The following paper (Mackey et al., 1989) presents evidence that 2 of these neurons, the left and right CB1 cells, produce presynaptic facilitation of the siphon sensory cells contributing to behavioral dishabituation and sensitization of the gill- and siphon-withdrawal reflex.

The double-labeling technique also located a pair of dopaminergic neurons in the cerebral ganglia which send axons to 
the abdominal ganglion. Since dopamine produces presynaptic inhibition of the siphon sensory neurons (Tomosky-Sykes, 1978; Abrams et al., 1984), it is possible that these dopaminergic neurons participate in behavioral inhibition of the reflex by feeding, copulation, or aversive stimulation such as tail shock (Advokat, 1980; Lukowiak, 1980; Lukowiak and Freedman, 1983; Krontiris-Litowitz et al., 1987; Mackey et al., 1987; Marcus et al., 1988).

The double-labeling technique could be applied to a number of similar problems in Aplysia. For example, it might be used to locate interganglionic serotonergic neurons involved in the control of locomotion, circadian rhythms, or osmotic regulation, or dopaminergic neurons involved in the control of opaline secretion. By using a different retrograde fluorescent dye combined with immunofluorescence, the strategy can be applied more generally to interganglionic neurons of almost any transmitter type. We have recently used this approach to locate a FMRFamide-immunoreactive neuron in the pleural ganglion that produces presynaptic inhibition of the siphon sensory neurons contributing to behavioral inhibition of the reflex by tail shock (Mackey et al., 1987; Hawkins and Small, 1988).

\section{References}

Abrams, T. W., V. F. Castellucci, J. S. Camardo, E. R. Kandel, and P. E. Lloyd (1984) Two endogenous neuropeptides modulate the gill and siphon withdrawal reflex in Aplysia by presynaptic facilitation involving cAMP-dependent closure of a serotonin-sensitive potassium channel. Proc. Natl. Acad. Sci. USA 81: 7956-7960.

Advokat, C. (1980) Modulation of defensive reflexes in Aplysia californica by appetitive stimulation. Behav. Neural Biol. 28: 253-265.

Bailey, C. H., R. D. Hawkins, M. C. Chen, and E. R. Kandel (1981) Interneurons involved in mediation and modulation of gill-withdrawal reflex in Aplysia. IV. Morphologial basis of presynaptic facilitation. J. Neurophysiol. 45: 340-360.

Bailey, C. H., R. D. Hawkins, and M. Chen (1983) Uptake of $(3 \mathrm{H})$ serotonin in the abdominal ganglion of Aplysia californica: Further studies on the morphological and biochemical basis of presynaptic facilitation. Brain Res. 272: 71-81.

Barber, A. (1982) Monoamine-containing varicosities in the neural sheath of a gastropod mollusc demonstrated by glyoxylic acid histofluorescence. Cell Tissue Res. 226: 267-273.

Bernier, L., V. F. Castellucci, E. R. Kandel, and J. H. Schwartz (1982) Facilitatory transmitter causes a selective and prolonged increase in adenosine $3^{\prime}$ ' '-monophosphate in sensory neurons mediating the gill and siphon withdrawal reflex in Aplysia. J. Neurosci. 2: 1682-1691.

Bolstad, G., T. Kalland, B. Srebo, and G. Stene-Larsen (1979) Modification of the glyoxylic acid method for visualization of catecholamines in vertebrate and invertebrate species. Comp. Biochem. Physiol. 62C: 61-65.

Brunelli, M., V. Castellucci, and E. R. Kandel (1976) Synaptic facilitation and behavioral sensitization in Aplysia: Possible role of serotonin and cAMP. Science 194: 1178-1181.

Carpenter, D., G. Bruse, S. Schanberg, and I. Kopin (1971) Serotonin and dopamine: Distribution and accumulation in Aplysia nervous and non-nervous tissues. Int. J. Neurosci. 2: 49-56.

Cash, D., and T. J. Carew (1989) A quantitative analysis of the development of the central nervous system in juvenile Aplysia californica. J. Neurobiol. 20: 25-47.

de la Torre, J. C., and J. W. Surgeon (1976) A methodological approach to rapid and sensitive monoamine histofluorescence using a modified glyoxylic acid technique: The SPG method. Histochemistry 49: 8193.

Eisenstadt, M., J. E. Goldman, E. R. Kandel, H. Koike, J. Koester, and J. H. Schwartz (1973) Intrasomatic injection of radioactive precursors for studying transmitter synthesis in identified neurons of Aplysia californica. Proc. Natl. Acad. Sci. USA 70: 3371-3375.

Frazier, W. T., E. R. Kandel, I. Kupfermann, R. Waziri, and R. E. Coggeshall (1967) Morphological and functional properties of identified neurons in the abdominal ganglion of Aplysia californica. J. Neurophysiol. 30: 1288-1351.
Glanzman, D. L., S. L. Mackey, R. D. Hawkins, A. Dyke, P. E. Lloyd, and E. R. Kandel (1989) Depletion of serotonin in the nervous system of Aplysia reduces the behavioral enhancement of gill withdrawal as well as the heterosynaptic facilitation produced by tail shock.

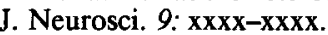

Goldstein, R. S. (1984) Immunocytochemical, histofluorescent, and ultrastructural studies of monoaminergic neurons and their processes in Aplysia. Ph.D. Dissertation, Columbia University, New York.

Goldstein, R. S., and J. H. Schwartz (1989) Catecholamine neurons in Aplysia: Improved light-microscopic resolution and ultrastructural study using paraformaldehyde and glutaraldehyde (FaGlu) cytochemistry. J. Neurobiol. 20: 203-218.

Goldstein, R., H. B. Kistler, H. W. M. Steinbusch, and J. H. Schwartz (1984) Distribution of serotonin-immunoreactivity in juvenile $A p l y$ sia. Neuroscience 11: 535-547.

Gospe, S. M., L. L. Cook, K. A. Crutcher, and W. A. Wilson (1981) Biochemical and histochemical studies of the effect of reserpine in Aplysia californica. Comp. Biochem. Physiol. 70C: 273-276.

Hawkins, R. D. (1981) Interneurons involved in mediation and modulation of gill-withdrawal reflex in Aplysia. III. Identified facilitating neurons increase $\mathrm{Ca}^{2+}$ current in sensory neurons. J. Neurophysiol. 45: 327-339.

Hawkins, R. D., and S. Schacher (1989) Identified facilitator neurons L29 and L28 are excited by cutaneous stimuli used in dishabituation, sensitization, and classical conditioning of Aplysia. J. Neurosci. 9: 4236-4245.

Hawkins, R. D., and S. A. Small (1988) An identified FMRFamideimmunoreactive neuron produces presynaptic inhibition of the siphon sensory neurons in Aplysia. Soc. Neurosci. Abstr. 14: 842.

Hawkins, R. D., V. F. Castellucci, and E. R. Kandel (198la) Interneurons involved in mediation and modulation of gill-withdrawal reflex in Aplysia. I. Identification and characterization. J. Neurophysiol. 45: 304-314.

Hawkins, R. D., V. F. Castellucci, and E. R. Kandel (1981b) Interneurons involved in mediation and modulation of gill-withdrawal reflex in Aplysia. II. Identified neurons produce heterosynaptic facilitation contributing to behavioral sensitization. J. Neurophysiol. 45: 315-326.

Jahan-Parwar, B., K. Rosza, J. Salanki, M. L. Evans, and D. O. Carpenter (1987) In vivo labeling of serotonin-containing neurons by 5,7-dihydroxytryptamine in Aplysia. Brain Res. 426: 173-178.

Kistler, H. B., Jr., R. D. Hawkins, J. Koester, H. W. M. Steinbusch, E. R. Kandel, and J. H. Schwartz (1985) Distribution of serotoninimmunoreactive cell bodies and processes in the abdominal ganglion of mature Aplysia. J. Neurosci. 5: 72-80.

Klein, M., and E. R. Kandel (1978) Presynaptic modulation of voltagedependent $\mathrm{Ca}^{2+}$ current: Mechanism for behavioral sensitization. Proc. Natl. Acad. Sci. USA 75: 3512-3516.

Klein, M., and E. R. Kandel (1980) Mechanism of calcium current modulation underlying presynaptic facilitation and behavioral sensitization in Aplysia. Proc. Natl. Acad. Sci. USA 77: 6912-6916.

Krontiris-Litowitz, J. K., M. T. Erickson, and E. T. Walters (1987) Central suppression of defensive reflexes in Aplysia by noxious stimulation and by factors released from body wall. Soc. Neurosci. Abstr. 13: 815 .

Liebeswar, G., J. E. Goldman, J. Koester, and E. Mayeri (1975) Neural control of circulation in Aplysia. III. Neurotransmitters. J. Neurophysiol. 38: 767-779.

Lindvall, O., and A. Björklund (1974) The glyocylic acid fluorescence histochemical method: A detailed account of the methodology for the visualization of central catecholamine neurons. Histochemistry 39: 97-127.

Longley, R. D., and A. J. Longley (1986) Serotonin immunoreactivity of neurons in the gastropod Aplysia californica. J. Neurobiol. 17:339358.

Lukowiak, K. (1980) CNS control over gill reflex behaviors in Aplysia: Satiation causes an increase in the suppressive control in older but not younger animals. J. Neurobiol. 11: 591-611.

Lukowiak, K., and L. Freedman (1983) The gill withdrawal reflex in sexually active Aplysia is suppressed. Can. J. Physiol. Pharmac. 61: 743-748.

Mackey, S. L., D. L. Glanzman, S. A. Small, A. M. Dyke, E. R. Kandel, and R. D. Hawkins (1987) Tail shock produces inhibition as well as sensitization of the siphon-withdrawal reflex of Aplysia: Possible behavioral role for presynaptic inhibition mediated by the peptide Phe-Met-Arg-Phe-NH $\mathrm{N}_{2}$. Proc. Natl. Acad. Sci. USA 84: 8730-8734. 
Mackey, S. L., E. R. Kandel, and R. D. Hawkins (1989) Identified serotonergic neurons LCB 1 and RCB 1 in the cerebral ganglia of $A p l y$ sia produce presynaptic facilitation of siphon sensory neurons. $J$. Neurosci. 9: 4227-4235.

Marcus, E. A., T. G. Nolen, C. H. Rankin, and T. J. Carew (1988) Behavioral dissociation of dishabituation, sensitization, and inhibition in Aplysia. Science 241: 210-213.

McCaman, M. W., D. Weinreich, and R. E. McCaman (1973) The determination of picomole levels of 5-HT and dopamine in Aplysia, Tritonia, and leech nervous tissues. Brain Res. 53: 129-137.

Ono, J., and R. E. McCaman (1984) Immunocytochemical localization and direct assays of serotonin-containing neurons in Aplysia. Neuroscience $11: 549-560$.

Rathouz, M. M., and M. D. Kirk (1988) Localization of catecholamines in the buccal ganglia of Aplysia californica. Brain Res. 458: 170-175.

Salimova, N. B., D. A. Sakharov, I. Milosevic, T. M. Turpaev, and L. Rakic (1987) Monoamine-containing neurons in the Aplysia brain. Brain Res. 400: 285-299.

Shkolnik, L. J., and J. H. Schwartz (1980) Genesis and maturation of serotonergic vesicles in identified giant cerebral neuron of Aplysia. J. Neurophysiol. 43: 945-967.
Simpson, I., B. Rose, and W. R. Lowenstein (1977) Size limit of molecules permeating the junctional membrane channels. Science 195: 294-296.

Tomosky-Sykes, T. K. (1978) Pharmacology of presynaptic facilitation of the gill-withdrawal reflex in Aplysia. Soc. Neurosci. Abstr. 4: 208.

Tritt, S. H., I. P. Lowe, and J. H. Byrne (1983) A modification of the glyoxylic acid induced histofluorescence technique for demonstration of catecholamines and serotonin in tissues of Aplysia californica. Brain Res. 259: 159-162.

Van der Kooy, D., and R. A. Wise (1980) Retrograde fluorescent tracing of substantia nigra neurons combined with catecholamine histofluorescence. Brain Res. 183: 447-452.

Weinreich, D., M. W. McCaman, R. E. McCaman, and J. E. Vaughn (1973) Chemical, enzymatic, and ultra-structural characterization of 5-hydroxytryptamine-containing neurons from the ganglia of Aplysia californica and Tritonia diomedia. J. Neurochem. 20:969-976.

Wieland, S. J., H. Zaininger, E. G. John, and A. Gelperin (1983) Dopamine and serotonin in Limax feeding: Distribution and metabolism. Soc. Neurosci. Abstr. 9: 75. 